\title{
Rhinitis caused by ninhydrin develops into occupational asthma
}

\author{
P. Piirilä, T. Estlander, M. Hytönen, H. Keskinen, O. Tupasela, M. Tuppurainen
}

Rhinitis caused by ninhydrin develops into occupational asthma. P. Piirilä, T. Estlander, M. Hytönen, H. Keskinen, O. Tupasela, M. Tuppurainen. OERS Journals Ltd 1997. ABSTRACT: Ninhydrin (2,2-dihydroxy-1,3-indanedione or 1,2,3-triketo-hydrindene hydrate) is a chemical used in the detection of free amino and carboxyl groups in proteins and peptides.

Allergic, immunoglobulin E (IgE)-mediated rhinitis caused by ninhydrin was diagnosed earlier in a 41 yr old woman working as a laboratory technician in a forensic laboratory. Despite handling ninhydrin only in a flow cabinet, symptoms of dyspnoea developed 6 months later. Peak flow was found to vary by $20 \%$ during working days. In the specific inhalation challenge it was shown that occupational asthma had also developed due to continuing slight exposure to ninhydrin. The titre of ninhydrin-specific IgE also increased from 0.6 to $1.1 \mathrm{kU} \cdot \mathrm{L}^{-1}$ in the follow-up.

This case stresses the importance of cessation of allergen exposure in occupational allergic rhinitis, in order to prevent asthma. Eur Respir J 1997; 10: 1918-1921.

Ninhydrin (2,2-dihydroxy-1,3-indanedione or 1,2, 3 -triketo-hydrindene hydrate; fig. 1) is a chemical that forms a blue colour with free amino and carboxyl groups of proteins and peptides. It is, therefore, used in chromatography for extracting allergens [1], as a dye in marking the skin for surgery and dermatology, and in fingerprint detection in forensic laboratories. A few cases of allergic contact eczema caused by ninhydrin have been reported $[2,3]$.

Allergic rhinitis caused by ninhydrin had been diagnosed previously in a laboratory technician working in a forensic laboratory and using ninhydrin to detect fingerprints on paper [4]. The patient continued her work using breathing protection to reduce exposure to ninhydrin. We report the development of her rhinitis into asthma as a result of the continued exposure to the allergen.

\section{Materials and methods}

Flow-volume spirometry was performed with a rolling seal spirometer (Vicatest 3; Jaeger Mijnhardt, Bunnile, The Netherlands) connected to a microcomputer (M909; Medicro, Kuopio, Finland). The reference values of VILJANEN

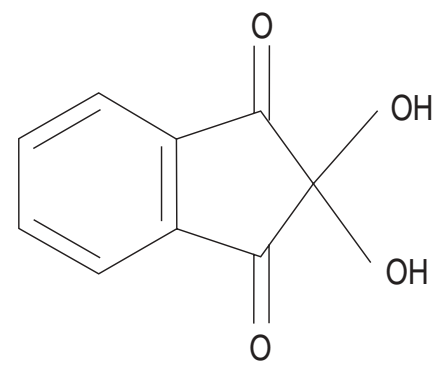

Fig. 1. - The molecular form of ninhydrin.
[5] were used. Histamine challenge tests were performed according to the method of SoviJÄRvi et al. [6] following measurement of forced expiratory volume in one second (FEV1) values with a Vitalograph bellow spirometer (Vitalograph, Buckingham, UK). A reduction of $15 \%$ in FEV1 was considered significant and the provocative dose causing a $15 \%$ reduction in FEV1 (PD15) was measured. The hyperresponsiveness was graded as strong (PD15 $<0.10 \mathrm{mg}$ ), moderate $(0.11-0.40 \mathrm{mg}$ ) or slight $(0.41-1.6 \mathrm{mg})$. The long-term workplace peak flow monitoring was performed with a mini-Wright peak flow meter according to the method of BURGE [7].

The ninhydrin challenge test was performed according to the principles of the European Academy of Allergology and Immunology $[8,9]$ in a $6 \mathrm{~m}^{3}$ challenge chamber. The specific challenge test was performed with paper infiltrated with ninhydrin as described earlier [4]. The placebo test was carried out with similar paper without ninhydrin. The FEV1 and peak expiratory flow (PEF) values during the challenge test procedure were measured by a portable pocket-sized spirometer (Micro Plus Spirometer, Micro Medical, Rochester, UK) [10]. The mucosal response of the nose was registered by anterior rhinoscopy; nasal status scoring was performed by an otorhinolaryngologist and using acoustic rhinometry (RHIN2000, SR Electronics APS, Lyngs, Denmark) [11]. The clinical symptoms and lung auscultation were also recorded.

The skin-prick tests to common inhalant allergens were performed as reported earlier [12] The skin-prick tests to ninhydrin, as well as the ninhydrin-specific IgE measurements were performed according to the method described earlier, when ninhydrin was tested as a $2 \%$ ninhydrin-human serum albumin (HSA) conjugate [4]. Values $<0.3 \mathrm{kU} \cdot \mathrm{L}^{-1}$ were considered negative. 


\section{Case report}

The patient was a nonsmoking woman aged $41 \mathrm{yrs}$, who had been working in a forensic laboratory for 12 yrs. She had no previous atopic tendency. Her ninhydrin-induced IgE-mediated allergic occupational rhinitis was diagnosed in October 1994, based on positive skin-prick tests, specific IgE antibodies to ninhydrin, and changes in nasal status and acoustic rhinometry during a specific challenge test [4]. The inhalation challenge tests with ninhydrin-containing paper did not induce changes in lung function. However, spirometry showed slight peripheral obstruction; only maximal expiratory flow when $25 \%$ of the forced vital capacity (FVC) remained exhaled (MEF25) and maximal expiratory flow when $50 \%$ of the FVC remained exhaled (MEF50) were slightly reduced, without response to bronchodilator. The histamine challenge test revealed slight bronchial hyperresponsiveness (PD15 $0.95 \mathrm{mg}$ ), although the lung function data were not addressed in the previous paper [4]. In peak flow surveillance no indications of asthma were found.

After the diagnosis of allergic rhinitis caused by ninhydrin, the patient continued working in the same laboratory, and used local nasal budesonide periodically.

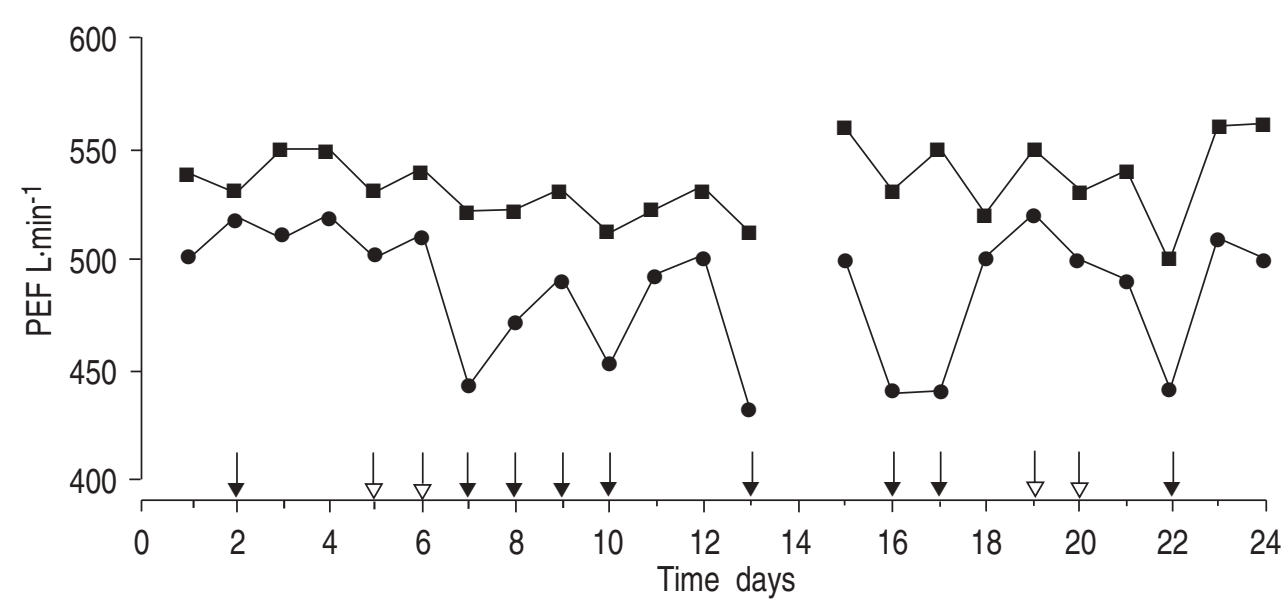

Fig. 2. - Peak expiratory flow (PEF) workplace follow-up during work with ninhydrin. $\mathbf{\square}$ : best PEF; $\bullet$ : lowest PEF; $\downarrow$ :ninhydrin work; $\downarrow$ : day off
She handled papers containing ninhydrin only in a flow cabinet. However, she still experienced rhinitis, a stuffy nose and hoarseness. Later, she also began to experience dyspnoea during exercise.

In March 1995, the histamine challenge test again indicated slight bronchial hyperreactivity (PD15 $0.83 \mathrm{mg}$ ). Spirometry showed slight peripheral obstruction (MEF50 $60 \%$ of predicted) without significant response to bronchodilator. The ninhydrin-specific IgE was $0.8 \mathrm{kU} \cdot \mathrm{L}^{-1}$, slightly higher than $0.6 \mathrm{kU} \cdot \mathrm{L}^{-1}$ measured in October 1994, at the time of diagnosis of the allergic rhinitis. In PEF surveillance, 16 and $20 \%$ variations were found connected with ninhydrin exposure (fig. 2). The reaction in the histamine challenge test after this workplace followup increased (PD15 decreased from 0.83 to $0.51 \mathrm{mg}$ ).

The patient continued working, using local budesonide for her rhinitis and regular inhaled nedocromil. In October 1995, spirometry again showed slight obstruction. The ninhydrin-specific $\operatorname{IgE}$ was $1.1 \mathrm{kU} \cdot \mathrm{L}^{-1}$. In the specific challenge test with ninhydrin-containing paper, an immediate $17 \%$ reduction in FEV1 and $19 \%$ fall in $\mathrm{PEF}$ were measured compared with the values measured before the challenge test (fig. 3). The otorhinolaryngologist found a significant change in the nasal status and there was a significant $15 \%$ decrease in acoustic rhinometry. The placebo challenge test was negative. The histamine challenge test indicated slight bronchial hyperresponsiveness: PD15 was 0.95 $\mathrm{mg}$ before and after these challenge tests.

Occupational asthma was diagnosed on the basis of these examinations. Treatment with inhaled budesonide was started, and the ninhydrin exposure was discontinued. In April 1996, the patient had no symptoms of rhinitis, only slight
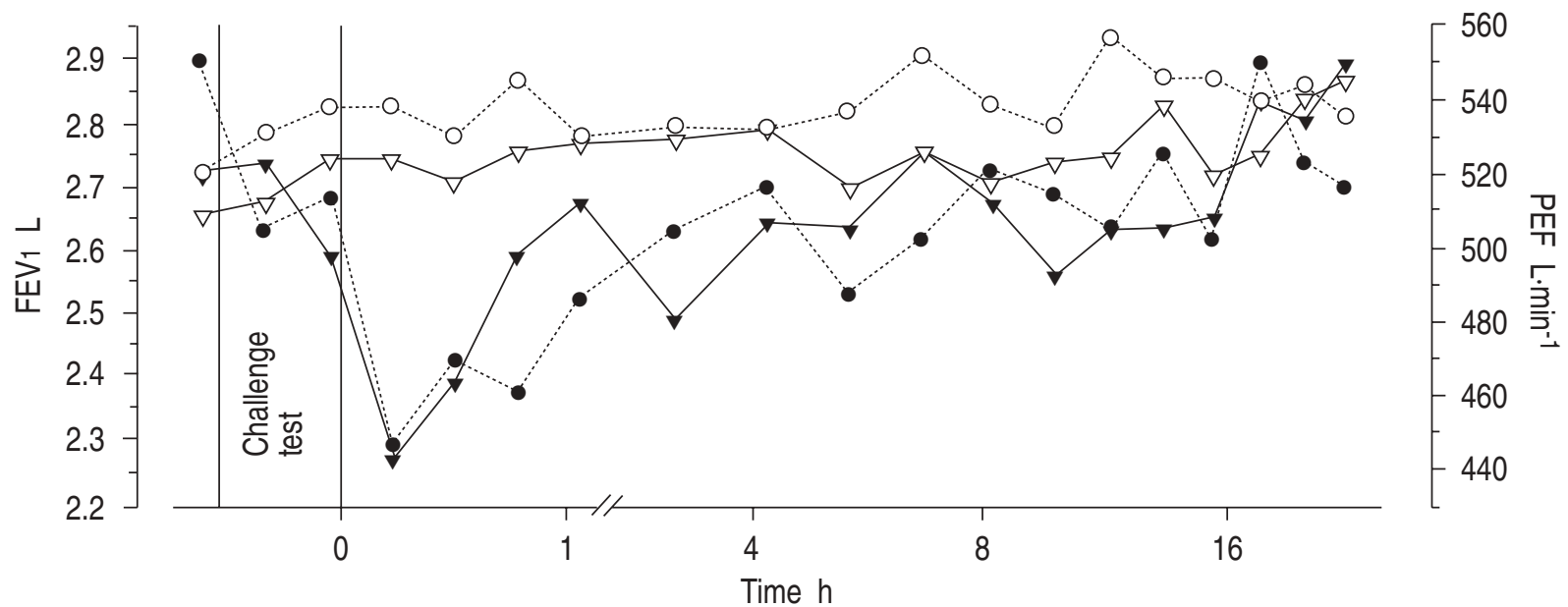

Fig. 3. - The results of a specific inhalation challenge test with ninhydrin infiltrated paper and a placebo test with paper without ninhydrin.

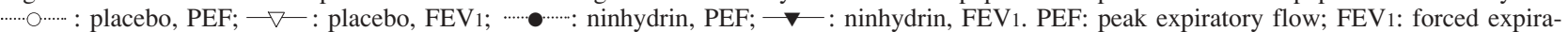
tory volume in one second. 
symptoms of dyspnoea during exercise. The ninhydrinspecific $\operatorname{IgE}$ was lower $\left(0.5 \mathrm{kU} \cdot \mathrm{L}^{-1}\right)$, but the histamine challenge test still showed slight bronchial hyperresponsiveness (PD15 $0.70 \mathrm{mg}$ ). Spirometry revealed slight obstruction without response to bronchodilator.

\section{Discussion}

In the case of the present patient, the diagnosis of allergic rhinitis had been verified, but exposure to the allergen continued, though at reduced level. The patient developed symptoms of the lower respiratory tract, while rhinitis symptoms also continued. After $1 \mathrm{yr}$, occupational allergic IgE-mediated asthma was diagnosed based on specific challenge test and PEF surveillance. Persistence of the earlier diagnosed allergic rhinitis was confirmed during the specific inhalation challenge test. The titre of ninhydrin-specific IgE increased simultaneously with the worsening symptoms, and decreased after cessation of the exposure.

Ninhydrin is used widely in chemistry, as well as in marking of the skin and detection of biological materials, but the number of published cases of contact allergy is small. Ninhydrin can cause skin irritation, and has already been shown to cause type IV allergic eczema $[2,3]$. An increasing number of other "contact allergens" have now been shown to induce type I allergic reactions, verified with specific $\operatorname{IgE}$ measurements or specific challenge tests, such as nickel [13, 14], acrylates [15] and epoxy resin [16].

It is commonly accepted that allergic rhinitis often precedes the development of asthma, although reports on allergic rhinitis turning into asthma are few. We are aware of only one earlier case report on occupational rhinitis developing into occupational asthma during continuing exposure [17]. In a study by BRODER et al. [18], approximately $6 \%$ of 579 persons with allergic rhinitis developed asthma in a 5 yr follow-up, compared to $2 \%$ of persons without allergic rhinitis. Children with allergic rhinitis have been reported to be seven times more likely to have asthma and wheezing illness than children without rhinitis symptoms [19]. A recent study has also shown that the highest incidence of occupational rhinitis occurs in younger age groups than the highest incidence of asthma, supporting the contention that rhinitis often precedes asthma [20].

When the allergic rhinitis of the present patient was diagnosed, the histamine challenge test showed slight bronchial hyperreactivity. In a study by BRAMAN et al. [21], patients with allergic rhinitis showing bronchial hyperresponsiveness were more likely to develop asthma than those without bronchial hyperresponsiveness. Therefore, in hindsight, it could have been suggested that the present patient had bronchial hyperresponsiveness as a risk factor and should, possibly, have been withdrawn from allergen exposure at an earlier stage.

It could be postulated that the patient already had mild asthma at the time of diagnosis of occupational rhinitis [4]. However, at that time she felt neither dyspnoea nor cough. In the peak flow monitoring, the variation was below $10 \%$ both on work days and during the weekends. In addition, at the time of the rhinitis diagnosis, the challenge test with ninhydrin-containing papers last- ed, at first, $30 \mathrm{~min}$, and, when repeated, $45 \mathrm{~min}$ (although this was not mentioned in the previous paper). Despite this, asthma could not be proven. One year later, asthma caused by ninhydrin was diagnosed in a ninhydrinchallenge test lasting $30 \mathrm{~min}$.

Re-exposure or continuing exposure to an occupational sensitizer allows the allergic process to continue and may induce allergic symptoms in other organs. Prolonged exposure after onset of symptoms has been shown to be one prognostic factor in the development of permanent asthma symptoms and continuous need for asthma medication [22-24]. In isocyanate-induced asthma, there is evidence that persistent exposure may even result in increased respiratory impairment $[22,25]$.

Symptoms of rhinitis may be overlooked as a sign of an allergic disease. Therefore, it is important to carefully examine, treat and follow patients with occupational allergic rhinitis, especially if they have bronchial hyperreactivity, and remove them early enough from allergen exposure, in order to prevent the disease progressing to asthma.

\section{References}

1. Richman PG, Cissel DS. A procedure for total protein determination with special application to allergenic extract standardization. J Biol Stand 1988; 16 (4): 225-238.

2. Schlacke KH, Fuchs Th. Allergisches Kontaktekzem auf Ninhydrin. Dermatosen 1989; 37: 179-180.

3 Roesler J, Kleinhans D. Contact allergy towards ninhydrin in a marking pen for patch testing. In: Frosch R, Dooms-Gossens A, Lachapelle J-M, Rycroft RJG, Scheper RJ, eds. Current Topics in Contact Dermatitis. Berlin, Heidelberg, New York, London, Springer-Verlag, pp. 342-344.

4. Hytönen M, Martimo KP, Estlander T, Tupasela O. Occupational IgE-mediated rhinitis caused by ninhydrin. Allergy 1996; 51: 114-116.

5. Viljanen AA. Reference values for spirometric, pulmonary diffusing capacity and body plethysmographic studies. Scand J Clin Invest 1982; 42 (Suppl. 159): 1-50.

6. Sovijärvi ARA, Malmberg LP, Reinikainen K, Rytilä P, Poppius H. A rapid dosimetric method with controlled tidal breathing for histamine challenge. Repeatability and distribution of bronchial reactivity in a clinical material. Chest 1993; 104: 164-170.

7. Burge PS. Single and serial measurements of lung function in the diagnosis of occupational asthma. Eur J Respir Dis 1982; 63 (Suppl. 123): 47-59.

8. Allergy practice forum. Guidelines for the diagnosis of occupational asthma. Clin Exp Allergy 1992; 22: 103-108.

9. Cartier A, Bernstein IL, Burge PS, et al. Guidelines for bronchoprovocation on the investigation of occupational asthma. J Allergy Clin Immunol 1989; 84: 823-828.

10. Keskinen H, Piirilä P, Nordman H, Nurminen M. Pocketsized spirometer for monitoring bronchial challenge procedures. Clin Physiol 1996; 16: 633-643.

11. Hytönen M, Sala E, Malmberg H, Nordman H. Acoustic rhinometry in the diagnosis of occupational rhinitis. $\mathrm{Am}$ $J$ Rhinol 1997 (in press).

12. Kanerva L, Estlander T, Jolanki R. Skin testing for immediate hypersensitivity in occupational allergology In: Menné T, Maibach HI, eds. Exogenous Dermatoses. Boca Raton, USA, CRC Press, 1991: 103-126. 
13. Malo JL, Cartier A, Doepner M, Nieboer E, Evans S, Dolovich J. Occupational asthma caused by nickel sulfate. J Allergy Clin Immunol 1982; 69: 55-59.

14. Estlander T, Kanerva L, Tupasela O, Keskinen H, Jolanki R. Immediate and delayed allergy to nickel with contact urticaria, rhinitis, asthma and contact dermatitis. Clin Exp Allergy 1993; 23: 306-310.

15. Savonius B, Keskinen H, Tuppurainen M, Kanerva L. Occupational respiratory disease caused by acrylates. Clin Exp Allergy 1993; 23: 416-424.

16. Kanerva L, Jolanki R, Tupasela $\mathrm{O}$, et al. Immediate and delayed allergy from epoxy resins based on diglycidyl ether of bisphenol A. Scand J Work Environ Health 1991; 17: 208-215.

17. Paggiaro PL, Rossi O, Lastrucci L, Pardi F, Pezzini A, Baschieri L. TDI-induced oculorhinitis and bronchial asthma. J Occup Health 1985; 27: 51-52.

18. Broder I, Barlow PP, Horton RJM. Epidemiology of asthma and allergic rhinitis in a total community, Tecumseh, Michigan. IV Natural history. J Allergy Clin Immunol 1974; 54: 100-110.
19. Anderson HR, Bland JM, Patel S, Peckham C. The natural history of asthma in childhood. J Epidemiol Community Health 1986; 40: 121-129.

20. Hytönen M, Kanerva L, Malmberg H, Martikainen R, Mutanen P, Toikkanen J. The risk of occupational rhinitis. Int Arch Occup Environ Health 1997; 69: 487-490.

21. Braman SS, Barrows AA, DeCotiis BA, Settipane GA, Corrao WM. Airway hyperresponsiveness in allergic rhinitis. A risk factor for asthma. Chest 1987; 91: 671-674.

22. Rosenberg N, Garnier R, Rouselin X, Mertz R, Gervais P. Clinical and socioprofessional fate of isocyanateinduced asthma. Clin Allergy 1987; 17: 55-61.

23. Hudson P, Cartier A, Pineau L, et al. Follow-up of occupational asthma caused by crab and various agents. $J$ Allergy Clin Immunol 1985; 76: 682-688.

24. Chan-Yeung M, Lam S, Koener S. Clinical features and natural history of occupational asthma due to Western Red Cedar. Am J Med 1982; 72: 411-415.

25. Pisati F, Baruffini A, Zedda S. Toluene diisocyanate induced asthma: outcome according to persistence or cessation of exposure. Br J Ind Med 1993; 50: 60-64. 